\title{
Rheological qualities of dough from mixture of flour and wheat bran and possible correlation between bra bender and mixolab Chopin equipments
}

\begin{abstract}
The rheological qualities of dough are determined during the mixing, extension and warming of the dough and they are closely correlated with the quality of the flour, however by increasing the amount of the dietary fibers, the qualities change, given that this leads to weakening of the proteins, respectively to the deterioration of gluten net. The equipment which is used in determining the rheological qualities is those of Bra bender: Farinograph, Extensograph, however, lately one also started to use Mixolab Chopin, which at the same time determines the quality of the proteins and starch.

The purpose of this study is to determine the rheological qualities of the dough obtained by mixing the flour of wheat cultivars from the region of Balkans with their bran, and the possible correlation of rheological parameters determined with Bra bender (Farinograph) and Mixolab Chopin equipments. Based on the obtained results either with the Bra bender equipment, or with Mixolab Chopin, better rheological qualities for production of bread are indicated by the bread which is obtained by mixing the flour of wheat cultivar Orovcanka with its bran.

High positive correlation coefficient is observed with regards to water absorption and development of dough, the stability of dough indicates a lower positive correlation coefficient, whereas the degree of softening indicates a medium negative correlation coefficient. With regards to the correlation coefficient among the values of Amylograph regarding the maximum viscosity and C3-torque Mixolab, as well as

Amylograph concerning the maximum viscosity and slope $\gamma$ Mixolab, in both cases we observed a medium positive correlation. Therefore, in general, the correlation between equipment Bra bender and Chopin Mixolab is positive, however not so prominent, respectively, variable.
\end{abstract}

Keywords: bra bender farinograph, bra bender amylograph, mixolab chopin, dough, coefficient of correlation
Volume 2 Issue 4 - 2016

\author{
Gafur Q Xhabiri,' Namik Durmishi,' Xhezair \\ Idrizi,' Ismail Ferati,' Ibrahim Hoxha \\ 'Faculty of Food Technology and Nutrition, University of Tetova, \\ Balkans \\ ${ }^{2}$ Food and Veterinary Agency, Kosovo
}

Correspondence: Gafur Q Xhabiri, Faculty of Food Technology and Nutrition, University of Tetova, R. of Macedonia, Balkans,Tel+3897I2638I7, Email gafur.xhabiri@unite.edu.mk

Received: March 3, 2016 | Published: May 31, 2016

\section{Introduction}

In order to obtain high quality attributes for the baking products, it is very important that one determines the rheological qualities of the dough, respectively of the flour and the mixtures. Usually, we use the equipment produced by Bra bender in order to measure the rheological attributes such as: Farinograph that indicates the information regarding the quality of the flour during mixing, Extensograph that indicates information on pulling and resistance of the dough, whereas for control of attributes of gelatinization of starch and indirectly for determination of $\alpha$-amylase activity, one uses Amylograph.

In 2005 the market was launched a new empirical rheological instrument by Chopin Technologies Company, ${ }^{1}$ the Mixolab device led to new information regarding the rheological behavior of dough during the bread making process because it allow to determine the mixing and heating properties of the wheat flour dough in one single test by using its extensive "Chopin" protocol option..$^{2-5}$ Mixolab can be applicable not only to wheat flour quality control, but to many other purposes including: development of gluten-free products, ${ }^{6}$ whole wheat studies, ${ }^{7}$ and effects of different hydrocolloids. ${ }^{8}$
The first part of the curve obtained by Mixolab indicates the degree of constant heating and it corresponds to the measurement of Farinograph, whereas the second part of the curve deals with the increase of temperature and it corresponds to the measurement obtained with Amylograph . For this reason, the value of the rotating twin in the maximum in second part of the curve $\left(\mathrm{C}_{3}\right)$ is as a result of starch turning into gelatinization and this can be compared to the peak of the curve which is obtained during the determination of maximum viscosity with Amylograph. ${ }^{9}$

Torbica et al. ${ }^{10}$ indicated that in determining the $\gamma$ slope from the obtained curve with Chopin Mixolab, one observes the speed of enzyme degradation that corresponds to the amylolytic activity which is obtained with Bra bender Amylograph.

Increase of the dietary fibers in the baking process, whereby the main source represents the bran of the cereals leads to serious problems in the quality of the bread, such as it increases the production of dough, to a more humid and shorter dough, to a lower fermentation tolerance, to a lower volume, to a crumb which is tense and nonelastic, in addition the change in smell and taste depend on the type of the fiber and of the bread. ${ }^{11}$ 
However, the incorporation of wheat bran into wheat dough greatly interferes with protein association and its further aggregation during heating. Presumably, fibers occupy the space of the proteins in the gluten network. ${ }^{12}$ In addition, a fiber also affects pasting characteristics of starch such as peak viscosity, breakdown and final viscosity. ${ }^{13}$ Rheological attributes, such are the water absorption, stability, elasticity, viscosity and pulling attributes are important for milling and confectionary industry in terms of predicting the parameters of processing the dough and attributes of the baked products. ${ }^{14}$

We can assert that this paper aims to bring to attention the impact of wheat bran in flour from the cultivars from the region of Balkans in the rheological attributes of the dough and possible correlation between obtained parameters with Bra bender equipment such as
Farinograph and Amylograph, with that of Chopin Mixolab.

\section{Materials and methods}

\section{Raw materials}

For the purpose of the study the flours obtained from wheat cultivars from the region of Balkans which are mostly used such are: Mila and Superzitarka from Croatia, Emeshe from Hungary, Novosadska Rana 2 and Pobeda from Serbia and Orovcanka from Macedonia. The bran obtained from the wheat cultivars is sieved in sieve with $800 \mu \mathrm{m}$ dimensions; they were stabilized and stored in the freezer until use. The mixing of the flour with their bran for performing the rheological analysis was prepared as per Table 1 .

Table I The ratio between flour and their bran thereof for the purpose of rheological qualities analysis

\begin{tabular}{|c|c|c|c|c|c|}
\hline $\begin{array}{l}\text { Wheat } \\
\text { Cultivar }\end{array}$ & $\begin{array}{l}\text { Flour } \\
(\%)\end{array}$ & $\begin{array}{l}\text { Bran } \\
(\%)\end{array}$ & $\begin{array}{l}\text { Wheat } \\
\text { cultivar }\end{array}$ & $\begin{array}{l}\text { Flour } \\
(\%)\end{array}$ & $\begin{array}{l}\text { Bran } \\
(\%)\end{array}$ \\
\hline Mila 0 & 100 & 0 & Orovcanka 0 & 100 & 0 \\
\hline M 1 & 95 & 5 & 01 & 95 & 5 \\
\hline M 2 & 90 & 10 & $\mathrm{O} 2$ & 90 & 10 \\
\hline M 3 & 85 & 15 & O 3 & 85 & 15 \\
\hline M 4 & 80 & 20 & O 4 & 80 & 20 \\
\hline $\begin{array}{l}\text { Novosadsk } \\
\text { rana } 0\end{array}$ & 100 & 0 & Emeshe 0 & 100 & 0 \\
\hline N 1 & 95 & 5 & E 1 & 95 & 5 \\
\hline $\mathbf{N} 2$ & 90 & 10 & E 2 & 90 & 10 \\
\hline N 3 & 85 & 15 & E 3 & 85 & 15 \\
\hline N 4 & 80 & 20 & E 4 & 80 & 20 \\
\hline Pobeda 0 & 100 & 0 & Superzitarka 0 & 100 & 0 \\
\hline $\mathbf{P} 1$ & 95 & 5 & S 1 & 95 & 5 \\
\hline $\mathbf{P} 2$ & 90 & 10 & S 2 & 90 & 10 \\
\hline P 3 & 85 & 15 & S 3 & 85 & 15 \\
\hline P 4 & 80 & 20 & S 4 & 80 & 20 \\
\hline
\end{tabular}




\section{Methods}

The studies with Bra bender Farinograh have been performed in compliance with ICC standard No.115/1 [15], whereby $300 \mathrm{~g}$ of flour with $14 \%$ mixture is mixed with water until reaching the optimum consistency of the dough $500 \mathrm{BU}$, whereby one determined the following parameters: water absorption (\%), dough development time, dough stability and the degree of softening of dough.

The studies with Bra bender Amylograph have been performed in compliance with ICC standard No.126/1, ${ }^{16}$ whereby one mixed $80 \mathrm{~g}$ of flour with $14 \%$ moisture with distilled water and the mixture is homogenized with glass stick and it is put in the amylograph dish with initial temperature of $25^{\circ} \mathrm{C}$, the temperature is increased with a norm of $1.5^{\circ} \mathrm{C} / \mathrm{min}$ until the maximum viscosity is determined.

The studies with Chopin Mixolab have been performed in accordance with the manual of 2005, the first who had access to this problem were Haros et al. ${ }^{7}$ and Collar et al. ${ }^{17}$ It measures in real time the torque (expresses in $\mathrm{Nm}$ ) produced by passage of the dough between the two kneading arms, thus allowing study of rheological and enzymatic parameters: dough rheological characteristics (hydration capacity, development time, etc.), protein reduction, enzymatic activity, gelatinization and gelling of starch. The procedure followed for the analysis of the mixing and pasting behavior to the Mixolab is the following: mixing speed 80rpm, tank temperature $30^{\circ} \mathrm{C}$, dough weight $75.0 \mathrm{~g}$, heating rate $2{ }^{\circ} \mathrm{C} / \mathrm{min}$, total analysis time takes 45 minutes.

\section{Statistical analysis}

All experiments were done in triplicate and data were expressed as mean and standard deviation. Correlation coefficients where $\mathrm{P}$ value less than 0.05 were considered statistically significant, between parameters obtained by Farinograph/Amylograph and Mixolab were calculated by using Data Analysis- Microsoft Office Excel 2007.

\section{Results and discussion}

Rheological qualities of the dough with Bra bender Farinograph and Amylograph (Table 2). Farinograph analysis indicates data on how the dough behaves during the mixing; respectively this method is based on the determination of the attributes of the dough based on the water absorption qualities and its behavior during the constant mixing period.

Water absorption is higher with the flour of wheat cultivar Orovcanka with $63.8 \%$, where the lowest with Pobeda with $60.3 \%$. By adding wheat bran in the selected wheat cultivar flours, the water absorption gradually increased, however this expressed in the percentage is higher with the flour mixtures of wheat cultivar Pobeda with its bran. These results are similar to the results obtained by Ahmed et al. ${ }^{18}$ who used insoluble fibers from $1 \mathrm{~g} / 100 \mathrm{~g}$ to $10 \mathrm{~g} / 100 \mathrm{~g}$ flour, where the water absorption increased from $58.70 \pm 0.40 \%$ for the pure flour to $71.00 \pm 0.51 \%$ for the flour which had added fibers of $10 / 100$ flour. All the flour types from the selected cultivars indicate a dough development time from 1.0 minute, addition of bran increased the dough development time; however a higher increase is observed with flour of cultivar Novosadska rana 2. These results are in correlation with the results obtained from Gomez et al. ${ }^{19}$ who had used a mixture of flour with dietary fibers with various origins.

The best dough stability is observed with the flour obtained from cultivar Novosadska rana 2 with 2.5 minutes, whereas the lowest is with the flour of cultivar Mila with only 0.5 minute. Addition of bran, increased the stability of the dough, for the bran of cultivars Pobeda and Emeshe addition of $10 \%$ bran indicated a higher stability with 7.0 and 6.0minutes, respectively. Best degree of softening is indicated by the dough obtained from cultivar Novosadska rana 2 with 35UF whereas the lowest is with cultivar Mila with 80UF. In general, by increasing the ratio of bran, the degree of softening of the dough is improved; however this happens due to the slower water absorption attribute of the bran (the dimensions of the bran).

According to Lai et al. ${ }^{20}$ there is a reciprocal correlation between the water amount that is absorbed and the time of the mixing, respectively the time of dough development. In order to obtain good bread, the mixture should be mixed until the mass achieves the optimum consistency of 500UF. However, during mixing, in order to hydrate the mixing particles flour-bran, which are larger than the particles of starch and gluten, takes much longer time. That is to say, if the percentage of fibers is larger as in our case whereby we increased up to $20 \%$ wheat bran, during the mixing they will be put within gluten web whereby the hydration process is slowed down, which in turn increases the time it takes for the dough to develop and the dough stability is increased which directly influences the qualitative number, respectively we obtain a better qualitative class.

Amylographic analysis of the dough initially it determines the viscosity of a mixture water-flour, in terms of the temperature and thus one can determine the amylolytic activity of certain flour or of certain mixture based on $\alpha$ - amylase. The results indicate that all the dough have a high amylolytic activity, whereas for baking the bread one requires an optimum viscosity of 450-650AU. By increasing the wheat bran in the flour, only with the cultivar Orovcanka we observed a decrease in maximum viscosity to the value of $860 \mathrm{AU}$, this by adding $20 \%$ of wheat bran to the flour.

\section{Rheological qualities of the dough with Mixolab Chopin}

As shown in Table 3, we can observe that by increasing the amount of bran from 5 to $20 \%$, increases the water absorption, however the dough from the cultivars Novosadska rana 2 and Emeshe indicate a higher water absorption compared to other dough, these results indicate a compliance with the results obtained by other researchers who have used different types of fibers such as Gomez et al. ${ }^{19}$ By increasing the amount of bran, the stability of dough increases; this is due to the increased interaction of hydrogen bonds by including the present hydroxide groups in the molecules. The dough of wheat cultivar Novosadska rana 2 indicates a higher stability compared to all the dough of other cultivars with $9.27 \pm 0.16$ minutes which increases further by adding bran, whereas the dough from the flour of cultivar Mila indicates a lower stability. These results are similar to the results of Banu et al. ${ }^{21}$ who have used wheat bran from $3 \%$ to $30 \%$, whereby by adding $20 \%$ of bran, the stability of dough increased and then it started to decrease. The dough development also increases with increase of the wheat bran.

The values of $\mathrm{C}_{1}$ and $\mathrm{C}_{2}$ expressed in $\mathrm{Nm}$ (the dough development and stability of proteins) are increased by adding bran, however a larger increase is observed with the dough of cultivar Orovcanka. According to Collar et al. ${ }^{17}$ the degree of milling and obtaining the white flour or un-screened flour is an important factor that influences the rheological attributes of the dough.

The preparation and baking phase describes the behavior of starch which is characterized by the gelatin capability of starch $\left(\mathrm{C}_{3}\right)$ and the 
activity of amylase $\left(\mathrm{C}_{4}\right)$, whereby the values of $\mathrm{C}_{3}$ in all the dough of cultivars, decreased by addition of bran, however a larger decrease was observed with Mila from $2.19 \pm 0.08 \mathrm{Nm}$ to $1.98 \pm 0.08 \mathrm{Nm}$ and the values of $\mathrm{C}_{4}$ for the dough decrease by adding bran to the mixture, given that bran mostly represent the cover of the grain which contains a high amount of $\alpha$-amylase, which is the cause of decrease of above mentioned values.

Table 2 The rheological qualities of the dough with Brabender equipment obtained from the mixture of wheat cultivar flours and their bran

\begin{tabular}{|c|c|c|c|c|c|c|}
\hline \multirow[b]{2}{*}{$\begin{array}{l}\text { The ration } \\
\text { flour/bran }\end{array}$} & \multicolumn{5}{|c|}{ Farinograph } & \multirow{2}{*}{$\begin{array}{l}\text { Amylograph } \\
\text { Max. viscosity (AU) }\end{array}$} \\
\hline & $\begin{array}{l}\text { Water } \\
\text { absorption } \\
(\%)\end{array}$ & $\begin{array}{l}\text { Dough } \\
\text { development } \\
\text { time (min) }\end{array}$ & $\begin{array}{l}\text { Dough } \\
\text { stability } \\
\text { (min) }\end{array}$ & $\begin{array}{l}\text { Degree of } \\
\text { softening } \\
\text { (UF) }\end{array}$ & $\begin{array}{l}\text { Quality number; quality } \\
\text { class }\end{array}$ & \\
\hline Mila 0 & $62.2 \pm 1.24$ & $1.0 \pm 0.50$ & $0.5 \pm 0.00$ & $80 \pm 4.0$ & $56.6 \mathrm{~B}_{1}$ & $1000 \pm 0.0$ \\
\hline M1 & $63.5 \pm 0.97$ & $1.5 \pm 0.01$ & $2.0 \pm 0.50$ & $75 \pm 5.0$ & $60.4 \mathrm{~B}_{1}$ & $1000 \pm 0.0$ \\
\hline M 2 & $66.0 \pm 0.80$ & $3.0 \pm 0.01$ & $3.0 \pm 0.00$ & $75 \pm 5.0$ & $62.4 \mathrm{~B}_{1}$ & $1000 \pm 0.0$ \\
\hline M 3 & $67.1 \pm 0.72$ & $1.5 \pm 0.66$ & $4.5 \pm 0.66$ & $75 \pm 5.0$ & $63.5 \mathrm{~B}_{1}$ & $1000 \pm 0.0$ \\
\hline M 4 & $70.9 \pm 1.21$ & $4.5 \pm 0.50$ & $1.5 \pm 0.25$ & $75 \pm 5.0$ & $66.2 \mathrm{~B}_{1}$ & $1000 \pm 0.0$ \\
\hline $\begin{array}{l}\text { Novosadska } \\
\text { rana } 0\end{array}$ & $62.0 \pm 1.05$ & $1.0 \pm 0.01$ & $2.5 \pm 0.00$ & $35 \pm 0.0$ & $71.3 \mathrm{~A}_{2}$ & $1000 \pm 0.0$ \\
\hline N 1 & $63.5 \pm 1.01$ & $1.0 \pm 0.01$ & $1.0 \pm 0.05$ & 0 & $100 \mathrm{~A}_{1}$ & $1000 \pm 0.0$ \\
\hline $\mathrm{N} 2$ & $68.0 \pm 0.75$ & $1.0 \pm 0.01$ & $1.0 \pm 0.05$ & 0 & $100 \mathrm{~A}_{1}$ & $1000 \pm 0.0$ \\
\hline N 3 & $68.7 \pm 0.85$ & $7.0 \pm 0.01$ & $5.0 \pm 0.25$ & 0 & $100 \mathrm{~A}_{1}$ & $1000 \pm 0.0$ \\
\hline N 4 & $71.8 \pm 0.90$ & $11.0 \pm 0.05$ & $2.5 \pm 0.50$ & $20 \pm 0.0$ & $91.2 \mathrm{~A}_{1}$ & $1000 \pm 0.0$ \\
\hline Pobeda 0 & $60.3 \pm 0.65$ & $1.0 \pm 0.01$ & $1.0 \pm 0.00$ & $70 \pm 5.0$ & $59.8 \mathrm{~B}_{1}$ & $1000 \pm 0.0$ \\
\hline P 1 & $61.5 \pm 0.84$ & $1.5 \pm 0.50$ & $1.5 \pm 0.10$ & $60 \pm 5.0$ & $65.2 \mathrm{~B}_{1}$ & $1000 \pm 0.0$ \\
\hline P 2 & $66.1 \pm 0.76$ & $2.5 \pm 0.50$ & $7.0 \pm 0.10$ & $50 \pm 5.0$ & $72.5 \mathrm{~A}_{2}$ & $1000 \pm 0.0$ \\
\hline P 3 & $68.1 \pm 0.88$ & $5.0 \pm 0.01$ & $5.0 \pm 0.50$ & $45 \pm 0.0$ & $78.0 \mathrm{~A}_{2}$ & $1000 \pm 0.0$ \\
\hline P 4 & $71.6 \pm 0.91$ & $6.0 \pm 0.01$ & $2.0 \pm 0.00$ & $55 \pm 5.0$ & $74.0 \mathrm{~A}_{2}$ & $1000 \pm 0.0$ \\
\hline Orovcanka 0 & $66.5 \pm 1.04$ & $1.0 \pm 0.01$ & $1.5 \pm 0.00$ & $60 \pm 2.0$ & $61.3 \mathrm{~B}_{1}$ & $1000 \pm 0.0$ \\
\hline O 1 & $68.5 \pm 0.76$ & $1.0 \pm 0.01$ & $1.5 \pm 0.10$ & $50 \pm 5.0$ & $65.4 \mathrm{~B}_{1}$ & $1000 \pm 0.0$ \\
\hline O 2 & $70.0 \pm 1.04$ & $4.0 \pm 0.01$ & $3.0 \pm 0.30$ & $40 \pm 5.0$ & $74.0 \mathrm{~A}_{2}$ & $1000 \pm 0.0$ \\
\hline O 3 & $72.4 \pm 1.42$ & $5.5 \pm 0.50$ & $2.5 \pm 0.50$ & $45 \pm 5.0$ & $73.3 \mathrm{~A}_{2}$ & $960 \pm 10$ \\
\hline $\mathrm{O} 4$ & $75.7 \pm 0.95$ & $5.5 \pm 0.50$ & $2.0 \pm 0.10$ & $45 \pm 0.0$ & $76.4 \mathrm{~A}_{2}$ & $860 \pm 10$ \\
\hline Emeshe 0 & $63.5 \pm 1.01$ & $1.0 \pm 0.01$ & $1.5 \pm 0.00$ & $45 \pm 5.0$ & $68.0 \mathrm{~B}_{1}$ & $1000 \pm 0.0$ \\
\hline E 1 & $65.0 \pm 0.85$ & $1.0 \pm 0.01$ & $1.5 \pm 0.00$ & $25 \pm 0.0$ & $74.9 \mathrm{~A}_{2}$ & $1000 \pm 0.0$ \\
\hline E 2 & $69.5 \pm 0.90$ & $6.0 \pm 0.50$ & $6.0 \pm 0.30$ & $30 \pm 5.0$ & $82.2 \mathrm{~A}_{2}$ & $1000 \pm 0.0$ \\
\hline E 3 & $72.8 \pm 0.65$ & $6.5 \pm 0.50$ & $4.5 \pm 0.15$ & $30 \pm 5.0$ & $80.4 \mathrm{~A}_{2}$ & $1000 \pm 0.0$ \\
\hline E 4 & $74.2 \pm 0.48$ & $8.5 \pm 0.86$ & $3.0 \pm 0.10$ & $45 \pm 0.0$ & $79.2 \mathrm{~A}_{2}$ & $1000 \pm 0.0$ \\
\hline Superzitarka 0 & $65.0 \pm 0.80$ & $1.5 \pm 0.01$ & $2.0 \pm 0.60$ & $60 \pm 2.0$ & $64.5 \mathrm{~B}_{1}$ & $1000 \pm 0.0$ \\
\hline S 1 & $65.5 \pm 0.65$ & $1.5 \pm 0.01$ & $2.0 \pm 0.20$ & $55 \pm 0.0$ & $65.2 \mathrm{~B}_{1}$ & $1000 \pm 0.0$ \\
\hline S 2 & $67.2 \pm 0.94$ & $5.5 \pm 0.50$ & $5.5 \pm 0.01$ & $50 \pm 5.0$ & $66.2 \mathrm{~B}_{1}$ & $1000 \pm 0.0$ \\
\hline S 3 & $68.6 \pm 0.90$ & $6.5 \pm 0.50$ & $5.0 \pm 0.50$ & $30 \pm 0.0$ & $71.3 \mathrm{~A}_{2}$ & $1000 \pm 0.0$ \\
\hline S 4 & $70.2 \pm 0.85$ & $7.0 \pm 0.01$ & $5.0 \pm 0.50$ & $30 \pm 0.0$ & $74.2 \mathrm{~A}_{2}$ & $1000 \pm 0.0$ \\
\hline
\end{tabular}


Table 3 The rheological qualities of the dough with Mixolab Chopin obtained from the mixture of wheat cultivar flours and their bran

\begin{tabular}{|c|c|c|c|c|c|c|c|c|c|}
\hline \multirow{3}{*}{$\begin{array}{l}\text { The ratio } \\
\text { flour/bran }\end{array}$} & \multicolumn{9}{|l|}{ Mixolab } \\
\hline & \multirow{2}{*}{$\begin{array}{l}\text { Water } \\
\text { absorption } \\
(\%)\end{array}$} & \multirow{2}{*}{$\begin{array}{l}\text { Dough } \\
\text { stability } \\
\text { (min) }\end{array}$} & \multirow{2}{*}{$\begin{array}{l}\text { Dough } \\
\text { development } \\
(\mathrm{min})\end{array}$} & \multirow{2}{*}{$\begin{array}{l}\mathrm{C}_{1} \\
(\mathrm{~N} \mathrm{~m})\end{array}$} & \multirow{2}{*}{$\begin{array}{l}\mathrm{C}_{2} \\
(\mathrm{~N} \mathrm{~m})\end{array}$} & \multirow{2}{*}{$\begin{array}{l}\mathrm{C}_{3} \\
(\mathrm{~N} \mathrm{~m})\end{array}$} & \multirow{2}{*}{$\begin{array}{l}\mathrm{C}_{4} \\
(\mathrm{~N} \mathrm{~m})\end{array}$} & \multirow{2}{*}{$\begin{array}{l}\mathrm{C}_{5} \\
(\mathrm{~N} \mathrm{~m})\end{array}$} & \multirow{2}{*}{$\begin{array}{l}\gamma \\
(\mathrm{Nm} / \mathrm{min})\end{array}$} \\
\hline & & & & & & & & & \\
\hline Mila 0 & $55.0 \pm 1.05$ & $4.85 \pm 0.08$ & $1.4 \pm 0.02$ & $1.05 \pm 0.01$ & $0.49 \pm 0.01$ & $2.19 \pm 0.08$ & $2.11 \pm 0.09$ & $3.01 \pm 0.28$ & $-0.164 \pm 0.01$ \\
\hline M 1 & $55.4 \pm 1.37$ & $4.72 \pm 0.87$ & $1.2 \pm 0.02$ & $1.15 \pm 0.01$ & $0.46 \pm 0.01$ & $1.81 \pm 0.06$ & $2.21 \pm 0.14$ & $3.14 \pm 0.32$ & $-0.008 \pm 0.01$ \\
\hline M 2 & $59.0 \pm 0.60$ & $5.10 \pm 0.43$ & $2.55 \pm 0.08$ & $1.09 \pm 0.02$ & $0.43 \pm 0.01$ & $1.92 \pm 0.08$ & $2.16 \pm 0.14$ & $3.36 \pm 0.38$ & $-0.002 \pm 0.01$ \\
\hline M 3 & $57.7 \pm 0.97$ & $5.42 \pm 0.12$ & $4.47 \pm 0.12$ & $1.13 \pm 0.02$ & $0.47 \pm 0.01$ & $2.05 \pm 0.08$ & $2.01 \pm 0.09$ & $3.04 \pm 0.34$ & $-0.022 \pm 0.01$ \\
\hline M 4 & $60.1 \pm 1.02$ & $5.00 \pm 0.55$ & $4.32 \pm 0.12$ & $1.13 \pm 0.02$ & $0.45 \pm 0.01$ & $1.98 \pm 0.08$ & $1.78 \pm 0.02$ & $2.78 \pm 0.28$ & $-0.07 \pm 0.01$ \\
\hline \multicolumn{10}{|l|}{ Novosadska } \\
\hline \multicolumn{10}{|l|}{ rana 0} \\
\hline N 1 & $56.9 \pm 1.34$ & $9.67 \pm 0.24$ & $1.42 \pm 0.02$ & $1.11 \pm 0.01$ & $0.54 \pm 0.01$ & $2.19 \pm 0.10$ & $2.11 \pm 0.09$ & $3.20 \pm 0.40$ & $-0.004 \pm 0.01$ \\
\hline N 2 & $60.0 \pm 1.01$ & $9.92 \pm 0.08$ & $5.95 \pm 0.36$ & $1.11 \pm 0.01$ & $0.5 \pm 0.01$ & $2.21 \pm 0.10$ & $2.08 \pm 0.08$ & $3.32 \pm 0.42$ & $-0.046 \pm 0.01$ \\
\hline N 3 & $61.2 \pm 1.20$ & $10.42 \pm 0.82$ & $4.42 \pm 0.32$ & $1.11 \pm 0.01$ & $0.51 \pm 0.01$ & $2.15 \pm 0.12$ & $2.05 \pm 0.08$ & $3.26 \pm 0.40$ & $-0.038 \pm 0.01$ \\
\hline N 4 & $62.8 \pm 1.64$ & $10.15 \pm 0.46$ & $3.32 \pm 0.26$ & $1.13 \pm 0.04$ & $0.54 \pm 0.01$ & $2.12 \pm 0.12$ & $1.96 \pm 0.06$ & $3.19 \pm 0.38$ & $-0.032 \pm 0.01$ \\
\hline Pobeda 0 & $55.0 \pm 1.05$ & $5.95 \pm 0.32$ & $1.43 \pm 0.02$ & $1.05 \pm 0.01$ & $0.48 \pm 0.01$ & $2.09 \pm 0.10$ & $2.03 \pm 0.08$ & $2.81 \pm 0.30$ & $-0.018 \pm 0.01$ \\
\hline P 1 & $54.4 \pm 0.64$ & $7.65 \pm 0.41$ & $1.32 \pm 0.02$ & $1.13 \pm 0.03$ & $0.46 \pm 0.01$ & $2.13 \pm 0.09$ & $2.09 \pm 0.08$ & $2.80 \pm 0.21$ & $-0.023 \pm 0.01$ \\
\hline P 2 & $58.2 \pm 0.85$ & $8.43 \pm 0.10$ & $3.85 \pm 0.20$ & $1.10 \pm 0.02$ & $0.47 \pm 0.01$ & $2.11 \pm 0.09$ & $1.98 \pm 0.06$ & $3.01 \pm 0.29$ & $-0.034 \pm 0.01$ \\
\hline P 3 & $58.8 \pm 0.90$ & $8.60 \pm 0.42$ & $3.42 \pm 0.26$ & $1.12 \pm 0.02$ & $0.49 \pm 0.01$ & $2.1 \pm 0.09$ & $1.92 \pm 0.06$ & $3.05 \pm 0.30$ & $-0.038 \pm 0.01$ \\
\hline P 4 & $60.7 \pm 0.76$ & $8.47 \pm 0.47$ & $3.25 \pm 0.28$ & $1.13 \pm 0.03$ & $0.5 \pm 0.01$ & $2.09 \pm 0.10$ & $1.82 \pm 0.06$ & $2.84 \pm 0.27$ & $-0.084 \pm 0.01$ \\
\hline Orovcanka 0 & $56.5 \pm 1.08$ & $8.10 \pm 0.64$ & $1.87 \pm 0.06$ & $1.08 \pm 0.01$ & $0.46 \pm 0.01$ & $2.06 \pm 0.10$ & $1.98 \pm 0.08$ & $2.75 \pm 0.28$ & $-0.01 \pm 0.01$ \\
\hline O 1 & $57.4 \pm 1.14$ & $8.38 \pm 0.70$ & $1.87 \pm 0.06$ & $1.11 \pm 0.02$ & $0.49 \pm 0.01$ & $2.01 \pm 0.08$ & $1.88 \pm 0.08$ & $2.65 \pm 0.24$ & $-0.038 \pm 0.01$ \\
\hline $\mathrm{O} 2$ & $58.8 \pm 0.82$ & $7.32 \pm 0.50$ & $3.2 \pm 0.16$ & $1.17 \pm 0.04$ & $0.5 \pm 0.01$ & $1.97 \pm 0.08$ & $1.80 \pm 0.08$ & $2.44 \pm 0.20$ & $-0.034 \pm 0.01$ \\
\hline O 3 & $62.5 \pm 1.04$ & $8.22 \pm 0.62$ & $2.67 \pm 0.12$ & $1.14 \pm 0.03$ & $0.49 \pm 0.01$ & $1.96 \pm 0.08$ & $1.66 \pm 0.02$ & $2.42 \pm 0.18$ & $-0.084 \pm 0.01$ \\
\hline $\mathrm{O} 4$ & $60.5 \pm 0.65$ & $8.43 \pm 0.60$ & $3.75 \pm 0.20$ & $1.15 \pm 0.05$ & $0.53 \pm 0.01$ & $1.93 \pm 0.08$ & $1.56 \pm 0.04$ & $2.55 \pm 0.22$ & $-0.106 \pm 0.01$ \\
\hline Emeshe 0 & $60.9 \pm 0.75$ & $6.55 \pm 0.22$ & $1.12 \pm 0.02$ & $1.12 \pm 0.03$ & $0.59 \pm 0.01$ & $2.23 \pm 0.14$ & $1.83 \pm 0.04$ & $2.63 \pm 0.23$ & $-0.112 \pm 0.01$ \\
\hline E 1 & $57.2 \pm 0.96$ & $8.63 \pm 0.10$ & $1.07 \pm 0.01$ & $1.14 \pm 0.03$ & $0.5 \pm 0.01$ & $2.1 \pm 0.12$ & $2.00 \pm 0.09$ & $2.83 \pm 0.28$ & $-0.006 \pm 0.01$ \\
\hline E 2 & $61.0 \pm 1.43$ & $8.78 \pm 0.32$ & $1.87 \pm 0.02$ & $1.16 \pm 0.03$ & $0.51 \pm 0.01$ & $2.12 \pm 0.12$ & $1.95 \pm 0.09$ & $3.01 \pm 0.31$ & $-0.054 \pm 0.01$ \\
\hline E 3 & $60.8 \pm 1.08$ & $8.87 \pm 0.38$ & $4.9 \pm 0.40$ & $1.14 \pm 0.03$ & $0.51 \pm 0.01$ & $2.06 \pm 0.10$ & $1.78 \pm 0.04$ & $2.79 \pm 0.28$ & $-0.074 \pm 0.01$ \\
\hline E 4 & $63.1 \pm 0.97$ & $9.45 \pm 0.42$ & $4.95 \pm 0.44$ & $1.12 \pm 0.02$ & $0.53 \pm 0.01$ & $2.06 \pm 0.10$ & $1.61 \pm 0.02$ & $2.58 \pm 0.25$ & $-0.124 \pm 0.01$ \\
\hline
\end{tabular}


Table Continued

\begin{tabular}{|c|c|c|c|c|c|c|c|c|c|}
\hline \multirow{3}{*}{$\begin{array}{l}\text { The ratio } \\
\text { flour/bran }\end{array}$} & \multicolumn{9}{|l|}{ Mixolab } \\
\hline & \multirow{2}{*}{$\begin{array}{l}\text { Water } \\
\text { absorption } \\
(\%)\end{array}$} & \multirow{2}{*}{$\begin{array}{l}\text { Dough } \\
\text { stability } \\
\text { (min) }\end{array}$} & \multirow{2}{*}{$\begin{array}{l}\text { Dough } \\
\text { development } \\
\text { (min) }\end{array}$} & $\mathrm{C}_{1}$ & $\mathrm{C}_{2}$ & $\mathrm{C}_{3}$ & $\mathrm{C}_{4}$ & $\mathrm{C}_{5}$ & $\gamma$ \\
\hline & & & & (N m) & (N m) & $(\mathbf{N} \mathbf{m})$ & $(\mathbf{N}$ m) & $(\mathbf{N} \mathbf{m})$ & $(\mathrm{Nm} / \mathrm{min})$ \\
\hline S 1 & $59.8 \pm 1.05$ & $5.85 \pm 0.18$ & $1.43 \pm 0.02$ & $1.09 \pm 0.02$ & $0.47 \pm 0.01$ & $2.08 \pm 0.10$ & $1.84 \pm 0.08$ & $2.74 \pm 0.25$ & $-0.06 \pm 0.01$ \\
\hline S 2 & $61.2 \pm 0.72$ & $7.84 \pm 0.24$ & $3.85 \pm 0.26$ & $1.11 \pm 0.02$ & $0.47 \pm 0.01$ & $2.09 \pm 0.10$ & $1.80 \pm 0.08$ & $2.81 \pm 0.28$ & $-0.045 \pm 0.01$ \\
\hline S 3 & $61.4 \pm 0.87$ & $8.29 \pm 0.30$ & $4.02 \pm 0.38$ & $1.09 \pm 0.02$ & $0.45 \pm 0.01$ & $2.07 \pm 0.09$ & $1.74 \pm 0.04$ & $2.92 \pm 0.29$ & $-0.078 \pm 0.01$ \\
\hline S 4 & $62.4 \pm 0.90$ & $7.92 \pm 0.45$ & $3.97 \pm 0.32$ & $1.12 \pm 0.02$ & $0.43 \pm 0.01$ & $1.98 \pm 0.08$ & $1.69 \pm 0.02$ & $2.84 \pm 0.28$ & $-0.087 \pm 0.01$ \\
\hline
\end{tabular}

The stopping of cooling indicates the retrograding attribute of starch $\left(\mathrm{C}_{5}\right)$ and it decreases with the increase of bran in the wheat flour, these data correspond with the results of Rosell et al. ${ }^{22}$ where they included different fibers such are fibruline, fibrex, exafine and swelite, in various ratios with flour. Slope or slope of curve between $\mathrm{C}_{3}$ and $\mathrm{C}_{4}$ in all the mixtures is negative.

\section{The correlation between the results obtained from} bra bender farinograph and Chopin Mixolab

The increase of dietary fibers, respectively the type of dietary fibers and their content have a significant impact in the water absorption attribute by the dough development time, the stability of dough and the degree of softening of dough; this occurs due to the slower water absorption ability of the fibers, whereby the important is the dimensions of the latter.

Water absorption - the absorption ability in addition to depending from the size of the particles that have been utilized (the dietary fibers and flour), the amount and the quality of gluten and starch gelatinization. The analysis on correlation of water absorption using Bra bender Farinograph and Chopin Mixolab is shown in Figure 1. From the results, we observed that there is a strong positive correlation with a correlation coefficient from $\mathrm{r}=0.810150858(\mathrm{p}<0.05)$ and $\mathrm{R}^{2}=0.6563$, which renders the important possibility for it to be used in the future for the determination of quality of the dough.

Dough development time - the dough development time is influence by the quality of protein and starch, as well as from the size of the particles of the utilized flour and bran. A better dough development time will be observed when the quality of gluten is very favorable. Whereas starch properties do not significantly influence the dough development time as it is the case of gluten properties. ${ }^{23}$

The analysis on correlation of dough development time using Bra bender Farinograph and Chopin Mixolab is shown in (Figure 2). From the results, we observed that there is a strong positive correlation with a correlation coefficient from $\mathrm{r}=0.841314215(\mathrm{p}<0.05)$ and $\mathrm{R}^{2}=0.7078$. The results are similar to Dapcevic et al. ${ }^{9}$ who have used nineteen samples of mercantile wheat and from the performed analysis they have obtained a strong positive correlation coefficient with $\mathrm{r}=0.9668$ $(\mathrm{p}<0.0001)$.

Dough stability-is mainly influenced by the quality of gluten and its resistance to the mixing. The analysis of correlation of dough stability by using Bra bender Farinograph and Chopin Mixolab is presented in Figure 3 . We observed that there is a poorly positive correlation with a correlation coefficient from $r=0.278265916(p<0.05)$ and $R^{2}=0.0774$. These data differ significantly from those of Rosel et al. ${ }^{22}$ who have used various commercial dietary fibers and obtained a correlation coefficient of $r=0.771(p<0.05)$.

Degree of softening-it is also influenced by the quality of gluten, however it is observed that the correlation coefficient by using Chopin Mixolab and Bra bender Farinograph is negative in average with a value of $r=-0.477465778(p<0.05)$ and $R^{2}=0.228$ (Figure 4).

\section{The correlation between the results obtained from bra bender amylograph and Chopin Mixolab}

The peak of the viscosity curve with Amylograph is mainly influenced by the quality of the starch granules which absorb water during the increase of the temperature and mixture, whereby in the moment of breaking of the envelope of granules, we observed a decrease in viscosity, while in the case of Mixolab tests, the maximum torque $\mathrm{C}_{3}$ obtained during heating with a constant heating rate and mixing of wheat dough was followed.

In Figure 5, the analysis of correlation between the results obtained from Bra bender Amylograph and $\mathrm{C}_{3}$ torque-Chopin Mixolab is presented, whereby the coefficient of correlation is positive in average with $\mathrm{r}=0.384975512(\mathrm{p}<0.05)$ and $\mathrm{R}^{2}=0.1482$. Perhaps the correlation coefficient could have been more favorable, but one has to take into account that all the utilized flour and the majority of the mixtures obtained with the wheat bran indicate a maximum viscosity (1000AU).

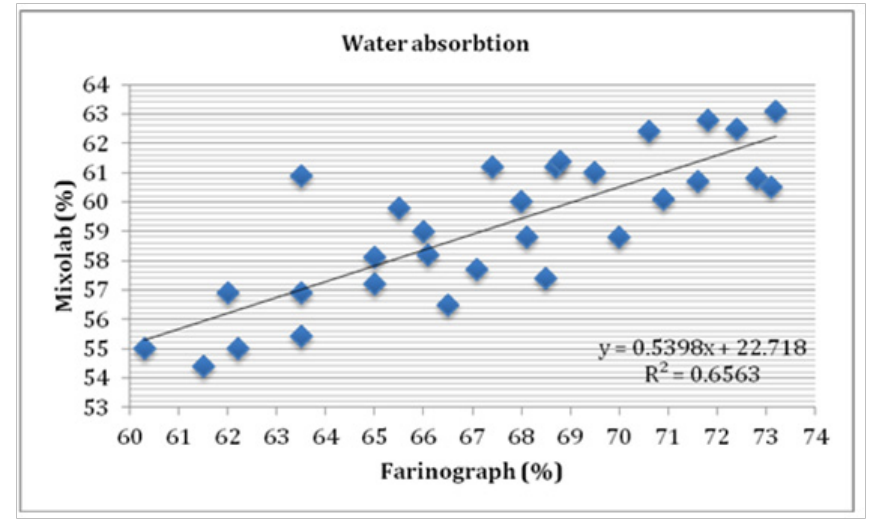

Figure I Correlation between water absorption obtained by Brabender Farinograph and Chopin Mixolab $(p<0.05)$. 


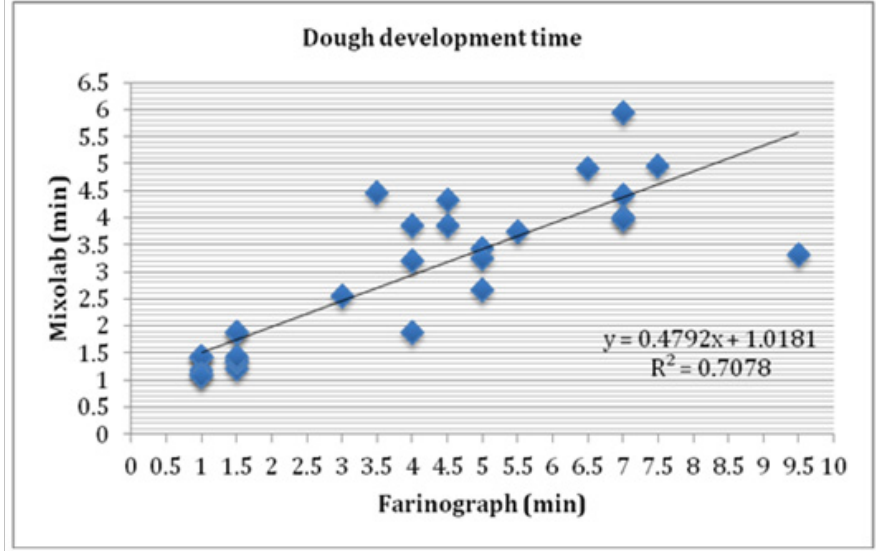

Figure 2 Correlation between dough development time obtained by Brabender Farinograph and Chopin Mixolab.



Figure 3 Correlation between dough stability obtained by Brabender Farinograph and Chopin Mixolab $(\mathrm{p}<0.05)$.

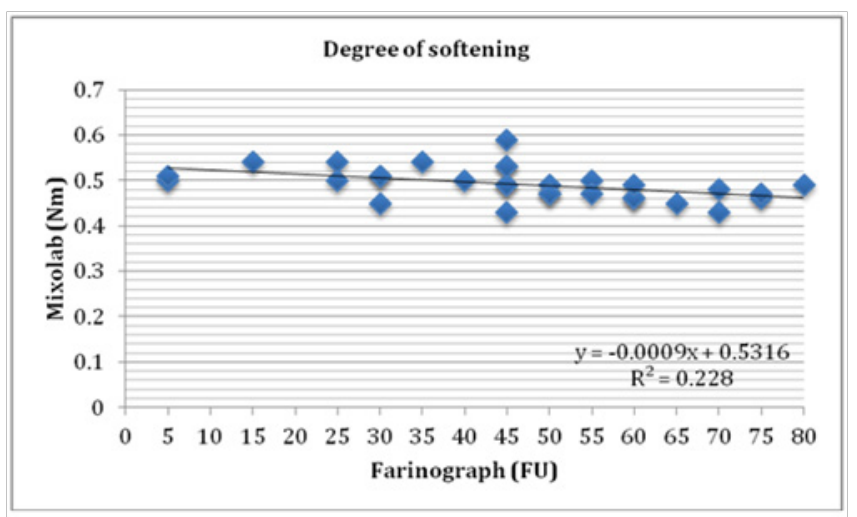

Figure 4 Correlation between degree of softening obtained by Brabender Farinograph and Chopin Mixolab $(\mathrm{p}<0.05)$.

In addition, from Figure 6 we can observe that the correlation coefficient between maximum viscosity with Bra bender Amylograph and slop $\gamma$ with Chopin Mixolap is very similar with the above mentioned correlation coefficient, it is positive in average with $\mathrm{r}=0.38843403(\mathrm{p}<0.05)$ and $\mathrm{R}^{2}=0.1509$, which indicates that the main factor is the maximum amylolytic activity. This coefficient is lower when compared to the results that are obtained by Stanojeska et al. ${ }^{24}$ who have used various types of flour with variable amylolytic activity and have obtained a correlation coefficient of $r=0.7921(p<0.05)$.

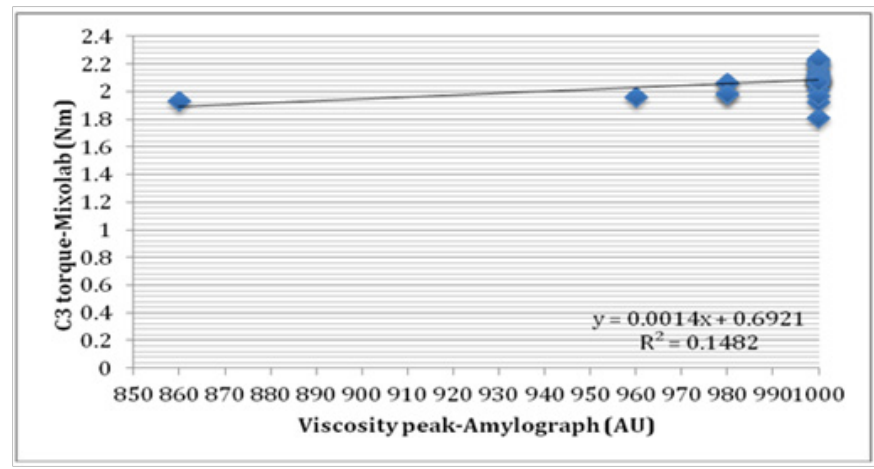

Figure 5 Correlation between peak viscosity (Amylograph) and C3 torque (Mixolab) $(p<0.05)$.

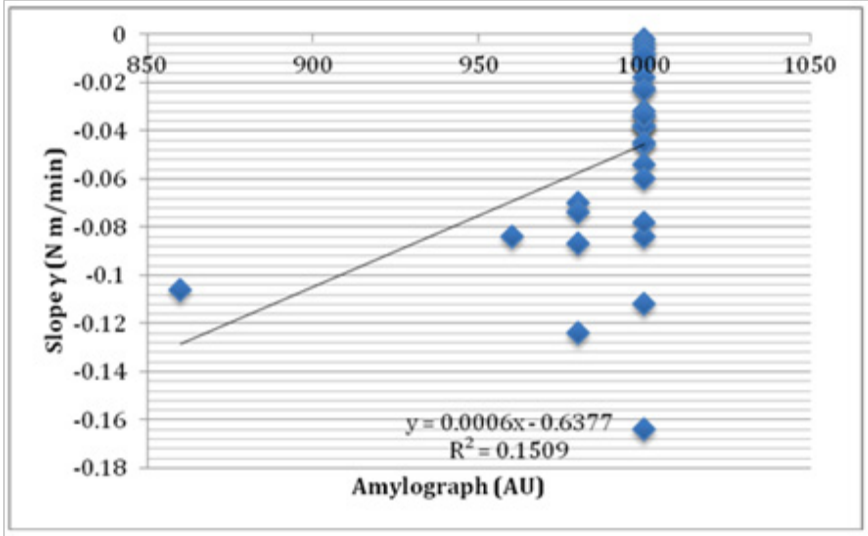

Figure 6 Correlation between peak viscosity (Amylograph) and slope $\gamma$ (Mixolab) $(p<0.05)$.

\section{Conclusion}

A more favorable rheological qualities of the dough for the bread production with the Bra bender equipment is obtained from the mixtures of flour of cultivar Orovcanka with its bran, whereas the mixtures that are obtained from the flour of cultivar Novosadska rana 2 and its bran indicate a favorable rheological qualities for the production of pasta. In addition, also with the Mixolab Chopin the mixtures that are obtained from cultivar Orovcanka flour and its bran indicate favorable attributes for bread production.

The determination of rheological qualities of dough from the flours of wheat cultivars from the region of Balkans and their bran by using the Bra bender (Farinograph and Amylograph) and Chopin Mixolab equipment, in general it indicated a favorable positive correlation. This water absorption and dough development have a very strong positive correlation, whereas the dough stability indicated a weak positive correlation, however on the other hand the degree of softening has indicated a medium negative correlation. Regarding the viscosity in both cases, we observed a medium positive correlation, which could be even higher, but the major parts of the mixtures indicated a maximum viscosity of 1000AU.

\section{Acknowledgements}

None. 


\section{Conflict of interest}

The author declares no conflict of interest.

\section{References}

1. Tripette \& Renaud Chopin. Chopin Mixolab User's Manual, France; 2005

2. Kahraman K, Sakiyan O, Ozturk S, et al. Utilization of Mixolab to predict the suitability of flours in terms of cake quality. European Food Research and Technology. 2008;227(2):565-570.

3. Ozturk S, Kahrman K, Tiftick B, et al. Predicting the cookie quality of flours by using Mixolab. European Food Research and Technology. 2008;227(5):1549-1554.

4. Codină GG, Mironeasa S, Bordei D, et al. Mixolab versus alveograph and falling number. Czech Journal of Food Sciences. 2010;28:185-191.

5. Codina GG, Mironeasa S, Mironeasa C. Variability and relationship among Mixolab and falling number evaluation based on influence of fungal $\alpha$-amylase addition. $J$ Sci Food Agric. 2012;92(10):2162-2170.

6. Marco C, Rosell CM. Breadmaking performance of protein enriched, gluten-free breads. European Food Research and Technology. 2008;227(4):1205-1213.

7. Haros M, Ferrer A, Rosell CM. Rheological behavior of whole wheat flour. IUFoST 13th World Congress of Food Sciences Technology, Nantes, France; 2006. p. 1139-1148.

8. Rosell CM, Collar C, Haros M. Assessment of hydrocolloid effects on the thermo-mechanical properties of wheat using the Mixolab. Food Hydrocolloid. 2007;21(3):452-462.

9. Dapcevic T, Handadjev M, Pojic M. Evaluation of the possibility to replace conventional rheological wheat flour quality control instruments with the new measurement tool-mixolab. Agriculturae Conspectus Scientificus. 2009;74(3):169-174.

10. Torbica A, Živančev D, Mastilović J, et al. Possibility of using sophisticated rheological method in quality determination of wheat flour. Food \& Feed Research. 2008;35(4):125-128.

11. Sinani A. Teknologjia e produkteve të pjekjes (Technology of baking products). Tirana, Albania; 2009. p. 274-276.

12. Gan Z, Galliard T, Ellis PR, et al. Effect of the outer bran layers on the loaf volume of wheat bread. Journal of Cereal Science. 1992;15(2):151-163.

13. Santos E, Rosell CM, Collar C. Gelatinization and retrogradation kinetics of high-fiber wheat flour blends: A calorimetric approach. Cereal Chemistry. 2008;85(4):455-463.
14. Jusra O, Hruskova M, Svec I. Bread features evaluation by NIR analysis. Czech Journal of Food Sciences. 2007;25:243-248.

15. Method for using the Brabender Farinograph. International association for cereal chemistry standard No 115/1. ICC; 1972.

16. ICC. Method for using the Brabender Amylograph. International association for cereal chemistry standard No 126/1; 1972.

17. Collar C, Bollain C, Rosell CM. Rheological behavior of formulated bread doughs during mixing and heating. Food Science and Technology International. 2007;13(2):99-107.

18. Ahmed J, Almusallam AS, Al-Salman F, et al. Rheological properties of water insoluble date fiber incorporated wheat flour dough. LWT - Food Science and Technology. 2013;51(2):409-416.

19. Gomez M, Ronda F, Blanco CA, et al. Effect of dietary fiber on dough rheology and bread quality. European Food Research and Technology. 2003;216:51-56.

20. Lai CS, Davis AB, Hosney RC. Production of whole wheat bread with good loaf volume. Cereal Chemistry. 1989;66(3):224-227.

21. Banu J, Stoenescu G, Ionescu SV. Effect of the addition of wheat bran stream on dough rheology and bread quality. The Annals of the University Dunarea de Jos of Galati, Fascicle VI-Food Technology. 2012;36(1):3952.

22. Rosell MC, Santos E, Collar C. Physical characterization of fiber-enriched bread dough's by dual mixing and temperature constraint using the Mixolab. European Food Research and Technology. 2010;231(47):499634.

23. Catteral P. Flour milling. In: SP Cauvain, LS Young editor. Technology of Breadmaking. 2nd ed. Gaithersburg, USA: Aspen Publishers Inc; 1995. p. 296-329.

24. Stanojeska M, Sokoloski B. Creating the correlation model at flour T-400 among Amylograph units and $\gamma$ slope of Mixolab curve. Journal of Hygienic Engineering and Design. 2012;1:247-250. 